\title{
Dimensões de provadores de roupas: um estudo de caso em quatro lojas de departamento de franquias nacionais
}

\author{
Dimensions of dressing rooms: a case study in four national franchise \\ department stores
}

\author{
BARROS, Bruno Xavier da Silva \\ Universidade Federal de Pernambuco, MSc. \\ barros_bruno@hotmail.com
}

\author{
ASSIS, Jéssica Priscila Lira de \\ Universidade Federal de Pernambuco, Bacharel \\ brunoxsbarros@gmail.com
}

SALAZAR, Manuel Henrique Coelho

Universidade Federal de Pernambuco, Bacharel

Ike.boarding@gmail.com

\begin{abstract}
RESUMO
Provadores de roupas em lojas de departamento são utilizados por um público extremamente diverso, o qual inclui pessoas de diferentes estaturas ou com sobrepeso. Nesse sentido, é de fundamental importância um local adequado destinado à experimentação das peças adquiridas pelo consumidor antes da efetuação da compra. Por esse motivo, o espaço precisa oferecer características essenciais, como ser dimensionalmente bem planejado e ordenado para se tornar eficiente. Entretanto, as inadequações neste tipo de ambiente incluem dificuldades de vestir determinados tipos de vestuário que envolvam flexão acentuada do tronco ou abdução dos membros superiores. Diante disso foi realizado um estudo de caso, avaliando antropometricamente os provadores em quatro lojas nacionais de departamento em uma cidade do nordeste brasileiro, para verificar as principais dificuldades encontradas no local, lançando mão de métodos observacionais e comparativos no sentido de entender a atividade e analisar as dimensões. $O$ experimento selecionou três voluntários distintos, sendo o primeiro de estatura elevada, o segundo de baixa estatura e o terceiro com sobrepeso. A análise sugeriu que os provadores estudados não atendem dimensionalmente a diversidade de tais biótipos, os quais precisam utilizar os mesmos, diante disso estabeleceu-se recomendações inclusivas para adequações dimensionais.
\end{abstract}

Ergonomia do Ambiente Construído, design inclusivo, provadores de roupa, lojas de departamento. 


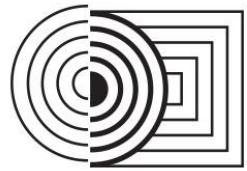

\section{$17^{\circ}$ ERGODESIGN \& USIHC 2019 \\ PUC-Rio, 11 a 13 de dezembro \\ Rio de Janeiro, RJ, Brasil}

$17^{\circ}$ Ergodesign - Congresso Internacional de Ergonomia e Usabilidade de Interfaces Humano Tecnológica: Produto, Informações Ambientes Construídos e Transporte

$17^{\circ}$ USIHC - Congresso Internacional de Ergonomia e Usabilidade de Interfaces Humano Computador

\begin{abstract}
Department store dressers are used by extremely diverse users, which includes people of different statures or overweight. In this sense, it is of fundamental importance a suitable place for the experimentation of the parts purchased by the consumer before the purchase. For this reason, space must offer essential features such as being dimensionally well-planned and orderly to become efficient. However, inadequacies in this type of environment include difficulties in wearing certain types of clothing that involve marked trunk flexion or upper limb abduction. Therefore, a case study was carried out, anthropometrically evaluating the dressing rooms in four national department stores in a northeastern city, to verify the main difficulties encountered in the place, using observational, comparative and user interview methods. The experiment selected three distinct volunteers, the first being tall, the second short, and the third overweight. The analysis suggested that the tasters studied do not dimensionally cater to all the diversity of people who need to use them, in the face of it inclusive recommendations for dimensional adjustments were established.
\end{abstract}

Built environment ergonomics, inclusive design, dressing rooms, department stores.

\title{
1. INTRODUÇÃO
}

Levando em consideração apenas o segmento de vestuário, onde se comercializa uma grande variedade de roupas, calçados e acessórios, evidencia-se o ambiente dos provadores de roupas, que é bastante procurado pela grande maioria dos consumidores. Os provadores de roupas são espaços reservados para que os clientes experimentem roupas e descubram como as mesmas ficam quando vestidas. O provador tem grande influência no processo de decisão no momento da compra. Com base nessa informação, é de total importância ressaltar os cuidados que precisam ser tomados na construção de um projeto destinado a esse ambiente. Neste contexto Bins Ely (2004), defende que toda atividade humana exige um determinado ambiente físico para sua realização. Portanto, caso se considere tanto a diversidade de atividades, quanto a diversidade humana, entende-se que as características do ambiente podem dificultar ou facilitar a realização dessas atividades.

A Ergonomia utiliza técnicas da Antropometria para adequar o ambiente de trabalho ao ser humano, propondo assim espaços e artefatos que se adaptem às características e limitações do corpo humano. Cada elemento que compõe o design precisa mais do que criar uma harmonia visual no ambiente, ele tem como princípio atender as necessidades e levar bemestar, conforto e segurança ao usuário. A Antropometria, junto à Ergonomia, gera condições ambientais e estruturais que facilitam e propõem mais qualidade nas atividades habituais do ser humano. Tornar um ambiente antropométrico exige uma percepção minuciosa sobre todo o espaço construído, desde as dimensões das paredes até os objetos contidos em seu entorno, a missão se torna ainda mais complexa quando o ambiente analisado tem dimensões reduzidas como os provadores de lojas de departamento que necessitam acolher um público bem diverso. Cabe considerar a atual prática de potencializar ao máximo o aproveitamento do solo urbano, o que compromete a definição dimensional nas edificações, pois muitas vezes o interesse de se construir mais é priorizado em relação à qualidade do espaço destinado ao ambiente. Como consequência, obtêm-se uma quantidade maior de espaços, mas oferece-se espaços reduzidos os quais implicam no comprometimento do desempenho da atividade, como impossibilidades de abdução total de membros superiores, ou flexão acentuada do tronco. 


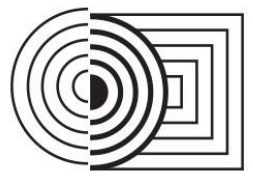

\section{$17^{\circ}$ ERGODESIGN \& USIHC 2019 \\ PUC-Rio, 11 a 13 de dezembro \\ Rio de Janeiro, RJ, Brasil}

$17^{\circ}$ Ergodesign - Congresso Internacional de Ergonomia e Usabilidade de Interfaces Humano Tecnológica: Produto, Informações Ambientes Construídos e Transporte

$17^{\circ}$ USIHC - Congresso Internacional de Ergonomia e Usabilidade de Interfaces Humano Computador

A corrente pesquisa teve como pressuposto o fato de que o espaço interno dos provadores de roupas das quatro lojas de departamento selecionadas não seria adequado a determinados públicos, como o de estatura elevada, o de baixa estatura e o com sobrepeso. Desta forma, o intuito da investigação foi a de verificar possíveis pontos de desconforto a partir da observação da usabilidade dos elementos físicos por parte destes públicos.

\section{FUNDAMENTAÇÃO TEÓRICA}

Os espaços destinados as áreas residenciais, comerciais ou públicas devem atender às exigências do ser humano em sua totalidade, pois se partindo da premissa de que o homem moderno passa apenas $25 \%$ do seu tempo no ambiente de trabalho e o resto do seu tempo no ambiente doméstico, meio de transporte e locais públicos (IIDA, 2005, p.412), é notável a necessidade da adequação desses ambientes, visando oferecer melhor qualidade de vida e satisfação para os usuários. No ponto de vista de Tramontin (2000), uma loja é frequentada por diferentes tipos de usuários, com diferentes características, temperamentos e necessidades, e por mais que a loja queira se especializar em um determinado segmento, ela deve estar atenta que mesmo os usuários que adotam as mesmas peculiaridades (idade, gênero, etnia), podem ter comportamentos diferenciados.

\subsection{Variabilidade biotípica e considerações antropométricas}

Ao projetar um ambiente, o profissional deve ter como prioridade o bem-estar e segurança do usuário, adequando cada compartimento de acordo com as medidas e necessidades humanas, com o intuito de garantir a seguridade e conforto dos mesmos (FERRAZ, 2010). Neste sentido tem-se a Antropometria, umas das principais ferramentas que promovem a otimização e aceitação do projeto, a fim de garantir a adequabilidade dos usuários no ambiente, proporcionando uma melhoria na qualidade da vida dos mesmos (PANERO e ZELNIK, 2013). A diversidade populacional é composta por indivíduos de diferentes tipos físicos ou biótipos. As medidas antropométricas visam estabelecer padrões para o perfil da população, e a padronização excessiva, pode atender alguns segmentos de mercado e ser totalmente inadequada para outros. Para que esse tipo de problema seja tratado objetivamente, deve-se ter conhecimento das variáveis que causam as diferenças do corpo humano (IIDA, 2005). Na visão de Panero e Zelnik (2013), embora exista essa grande diversidade na população, essas variáveis envolvidas não podem afetar a interface entre usuário e ambiente, ou seja, o ambiente projetado deve ser construído ou adaptado ao ser humano, garantindo conforto, segurança e uma vivência eficiente e alegre.

As características antropométricas da população utilizadora são distinguidas por dois tipos básicos de dimensões corporais com importância no projeto em espaços interiores, são eles: estruturais (também conhecidos como estáticos) que dizem respeito às dimensões estruturais fixas do corpo humano. O segundo tipo de dados antropométricos são os e os funcionais (também conhecidos como dinâmicos). Estes dados também incluem a medida do alcance e espaço livre em condições operacionais (SANTOS e FUJÃO, 2003). Neste sentido, a zona de alcance preferencial pode ser definida como a zona ou espaço na qual o objeto pode ser convenientemente alcançado, isto é, sem um esforço excessivo. É descrita pelos movimentos dos membros superiores na articulação medida do ombro até a ponta do dedo numa série de arcos para cada mão. A figura 1 explana exemplos de deslocamentos em Antropometria Dinâmica. 
$17^{\circ}$ ERGODESIGN \& USIHC 2019

PUC-Rio, 11 a 13 de dezembro

Rio de Janeiro, RJ, Brasil $17^{\circ}$ Ergodesign - Congresso Internacional de Ergonomia e Usabilidade de Interfaces Humano Tecnológica: Produto, Informações Ambientes Construídos e Transporte

$17^{\circ}$ USIHC - Congresso Internacional de Ergonomia e Usabilidade

de Interfaces Humano Computador

Figura 1: Exemplos de antropometria dinâmica. Fonte: lida (2005).

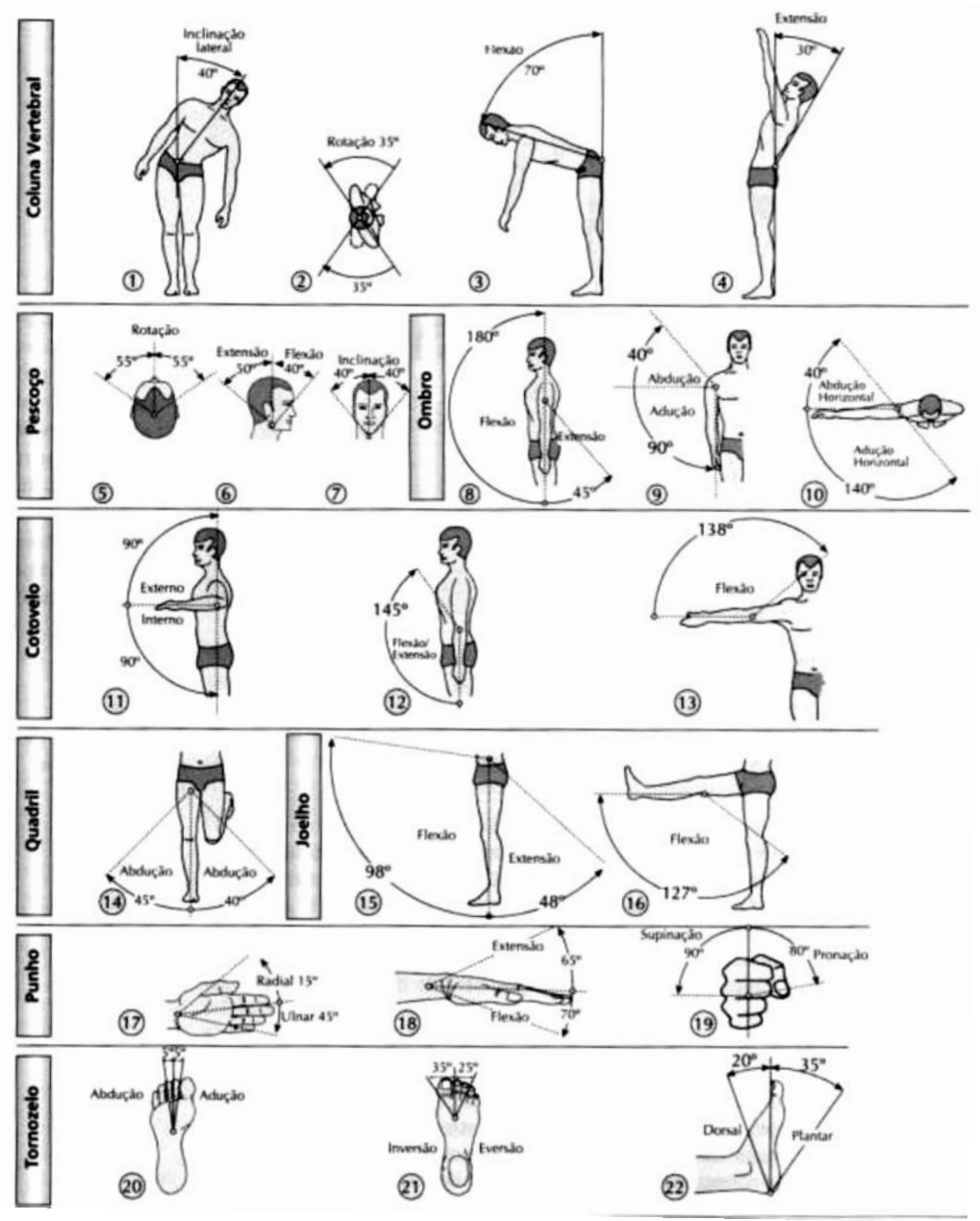

A imagem apresenta valores médios dos movimentos voluntários, ou seja, aqueles que podem ser feito pelo próprio indivíduo. Existe ainda uma grande variedade de movimentos passivos, ligeiramente superiores a esses que são realizados com o auxílio de outras pessoas (IIDA, 2005).

Provadores compõem-se de um único ambiente que geralmente está localizado em um espaço reservado da loja, esse espaço pode ser dividido em pequenas cabines. Os provadores geralmente tem seu uso restrito, onde só é permitida a entrada de um único indivíduo por cabine, oferecendo assim a privacidade dos usuários no ambiente. De acordo com Panero e Zelnik (2013 p.204), "os provadores devem acomodar o corpo humano nas várias posições assumidas ao experimentar uma peça de roupa". Para que essa premissa seja posta em prática, o espaço destinado aos provadores necessita proporcionar certos elementos dimensionais para se tornarem eficientes. Os autores sugerem dimensões para projetar uma cabine e ressaltam a importância de se estabelecer limites corporais relativos a pessoas de maiores e menores estaturas, uma vez que, nas lojas, podem não existir provadores com diferentes tamanhos para atender a grande diversidade de biótipos existente entre seus 


\section{$17^{\circ}$ ERGODESIGN \& USIHC 2019}

PUC-Rio, 11 a 13 de dezembro

Rio de Janeiro, RJ, Brasil $17^{\circ}$ Ergodesign - Congresso Internacional de Ergonomia e Usabilidade de Interfaces Humano Tecnológica: Produto, Informações Ambientes Construídos e Transporte

$17^{\circ}$ USIHC - Congresso Internacional de Ergonomia e Usabilidade de Interfaces Humano Computador

consumidores. Com base nessas informações Panero e Zelnik (2013), sugerem que, para um provador atender de forma adequada a diversos usuários, praticando constantes movimentos na realização da troca de roupa, é necessário conter dimensões mínimas de 147,3cm de largura por $91,4 \mathrm{~cm}$ de profundidade. A largura indicada para a área das portas, recomendadas pelos autores, deve ser de no mínimo $61 \mathrm{~cm}$, considerando o espaço que as mesmas ocupam no interior da cabine, ponderando ainda o espaço que os usuários necessitam ao adentrar no ambiente com um volume extra de objetos, além das suas próprias proporções (figura 2).

Figura 2: Dimensionamento para provadores. Fonte: Panero e Zelnik (2013).
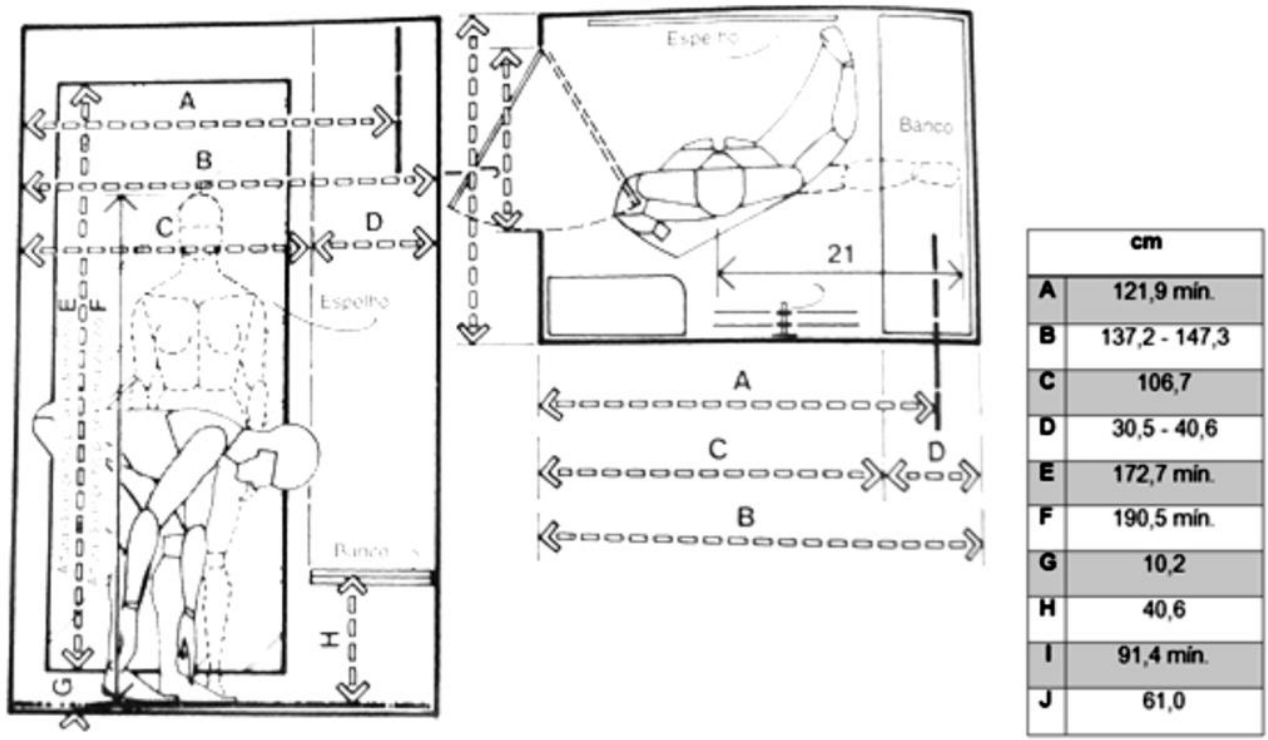

No que se refere aos componentes que fazem parte do interior da cabine, Panero e Zelnik (2013) recomendam que o mobiliário utilizado como apoio para que os usuários possam sentarse na realização das suas atividades tenha sua a altura máxima de $40,6 \mathrm{~m}$ e a profundidade do mesmo seja de $30,5 \mathrm{~m}$, tendo em vista a diversidade de bióticos que irão se beneficiar desse artefato. Ao correspondente dimensionamento do espelho existe uma alteração entre os gêneros femininos e masculinos, no feminino o recomendado a altura de $172,7 \mathrm{~m}$ já para o masculino o mínimo indicado é de 190,5m. Panero e Zelnik (2013), sugerem que os ganchos para roupas sejam fixados na parede estabelecendo um limite de altura, considerando as pessoas de menores estaturas. A altura sugerida pelos autores é de no máximo 182,9m visando atender homens e mulheres de diferentes estaturas de modo seguro e confortável.

\section{METODOLOGIA}

Para a execução da investigação, lançou-se mão do método Observacional associado a parte do conceito da fase de Problematização Ergonômica proposta pela Metodologia de Intervenção Ergonomizadora do Sistema Humano-Tarefa-Máquina. Para tanto, foi acompanhada a execução da tarefa, solicitando que cada voluntário utilizasse a cabine para trocar oito peças de vestimenta, variando entre peças para a parte superior e inferior do corpo. Para o voluntário do gênero masculino, fora designado um pesquisador do gênero masculino para acompanhar o processo e, para as voluntárias do gênero feminino, designou-se uma pesquisadora do gênero 
feminino para tal acompanhamento. Todo o procedimento fora fotografado, excluindo as primeiras imagens por se tratarem do período de habituação com a câmera. Um total de 312 fotografias foram captadas e, a partir de então, analisadas no sentido de selecionar as imagens mais contundentes para exposição das situações de inadequação do espaço de cada cabine sob a ótica do biotipo de cada usuário voluntário.

Para seleção dos voluntários, utilizou-se a Amostragem Intencional, cuja seleção é baseada no conhecimento sobre a população e o propósito do estudo. Deste modo, captamos a colaboração de três voluntários de características biotípicas distintas, a saber: 1. Usuário 1, do gênero feminino, 23 anos de idade, pesando $54 \mathrm{~kg}$ e 1,83m de estatura (classificado nesta pesquisa como "estatura elevada"); 2. Usuário 2, do gênero masculino, 27 anos de idade, pesando $107 \mathrm{~kg}$ e $1,68 \mathrm{~m}$ de estatura (baseado em seu IMC, classificado nesta pesquisa como "sobrepeso"; Usuário 3, do gênero feminino, 24 anos de idade, pesando 48kg e 1,46m de estatura (classificado nesta pesquisa como "estatura baixa"). A pesquisa foi aprovada pelo comitê de ética e os termos de consentimento livre e esclarecido foram apresentados e assinados pelos voluntários.

No que tange à seleção dos locais do estudo de caso, foram identificadas as quatro principais lojas de departamento da cidade onde ocorreu o estudo, as quais são conhecidas em todo o Brasil por serem franquias nacionais. Todas as lojas autorizaram a pesquisa mediante a garantia de sigilo quanto ao nome de cada estabelecimento.

\section{RESULTADOS}

\subsection{Verificação antropométrica das cabines}

\subsubsection{Provador da loja de departamento 1}

O dimensionamento do primeiro provador analisado (figura 3) apresenta $1 \mathrm{~m}$ de largura, seguindo as recomendações de Panero e Zelnik (2013), que sugerem o mínimo de 91,4m de largura para cada cabine, por outro lado o espaço não atende as dimensões de profundidade desejada, oferecendo apenas 1,20m quando o recomendado é de $1,473 \mathrm{~m}$, esse tipo de inadequação, além de dificultar as práticas de constantes movimentos na realização da troca de roupa, pode causar lesões graves ou desconfortos, colocando em risco a integridade física dos consumidores. 
Figura 3: Provador da loja de departamento 1. Fonte: Capturado pelo autor para a pesquisa (2019).

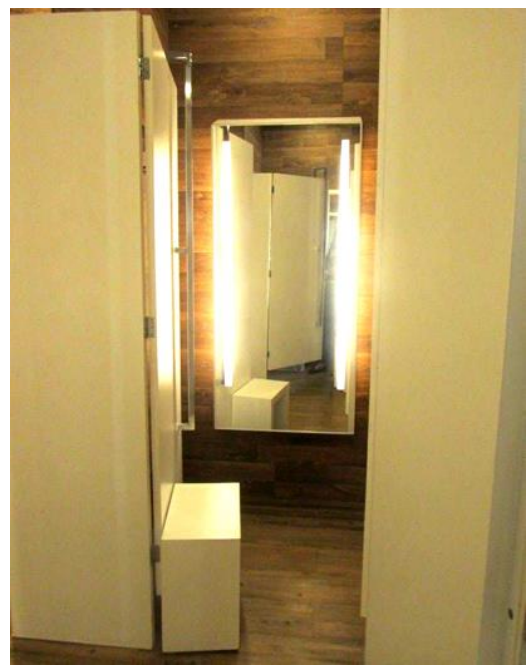

O espaço destinado para as portas, que são confeccionadas em MDF medindo 70 centímetros, encaixando-se dentro das recomendações de Panero e Zelnik (2013) que aconselham que para os provadores serem facilmente acessados devem medir no mínimo 61. Na análise sobre o mobiliário, observou-se que 0 assento oferecido pelo estabelecimento, apresenta proporções abaixo das recomendações de Panero e Zelnik (2013), o banco possui 40 de largura, atingindo um pouco mais que a largura mínima sugerida que é de 30,5 podendo chegar a máxima de 40,6. Em relação a altura do mobiliário, a dimensão sugerida pelos autores para a banqueta é de $40,6 \mathrm{~cm}$ porém o mobiliário possui apenas $35 \mathrm{~cm}$, essa proporção abaixo do recomendado pode interferir na prática das atividades.

Figura 4: Dimensionamento geral dos provadores da loja 1: Fonte: Elaborado pelo autor para a pesquisa (2019).

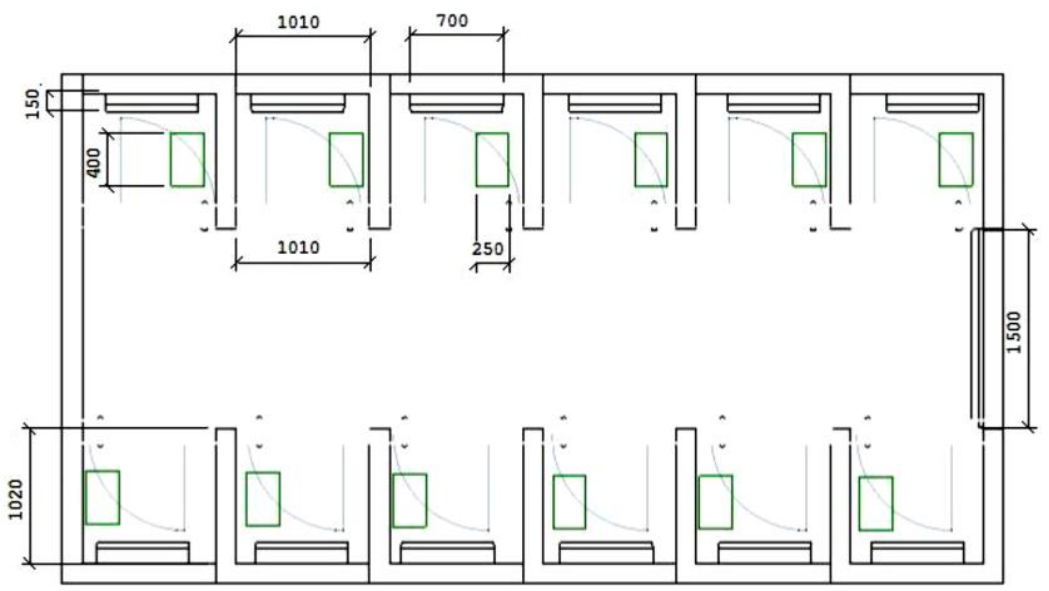

O estudo analisou também, a altura dos suportes que contém os ganchos que suspendem os objetos no interior das cabines. Os atuais suportes, estão fixados em uma das paredes, a uma altura de 1,60m, correspondendo a sugestão de Panero e Zelnik (2013) que é de 1,829, porém, 
essa altura necessita ser analisada levando em consideração o público que irá utilizar o ambiente, devido a grande diversidade de biótipos.

\subsubsection{Provador da loja de departamento 2}

As dimensões do segundo provador analisado (figura 5) são de $1 \mathrm{~m}$ de largura, seguindo as recomendações de Panero e Zelnik (2013), que sugerem o mínimo de 91,4c de largura para cada cabine, no entanto, o ambiente não oferece as dimensões mínimas em relação a profundidade, que é de apenas $1.10 \mathrm{~m}$, quando o recomendado é de $1,47 \mathrm{~m}$, esse tipo de inadequação, além de dificultar a mobilidade do usuário, pode causar lesões graves ou desconfortos, colocando em risco a integridade de seus consumidores.

Figura 5: Provador da loja de departamento 2. Fonte: Capturado pelo autor para a pesquisa (2019).

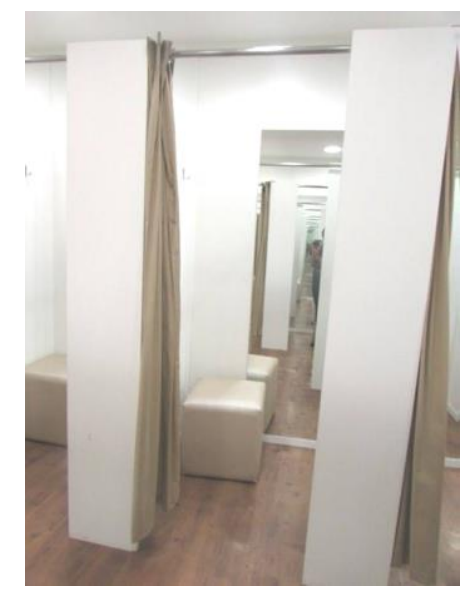

A área destinada para as portas, que nesta loja são confeccionadas em tecido, medem cada uma 1m, encaixando-se dentro das recomendações de Panero e Zelnik (2013), que aconselham que cada provador tenha no mínimo $61 \mathrm{~cm}$, porém, nesse caso, as cabines comportam duas laterais de segurança, as mesmas evitam que a cortinas fiquem entreabertas, o que oferece mais conforto ao consumidor, medindo $14 \mathrm{~cm}$ cada uma, reduzindo a área total da porta de $1 \mathrm{~m}$ para 72. Podemos analisar ainda que, mesmo sofrendo a redução, a área destinada as portas das cabines encontra-se com suas dimensões na média sugerida, mas vale ressaltar, que geralmente os consumidores ao acessar as cabines estão portando um volume extra de produtos, o que dificulta a entrada no ambiente, se o mesmo oferecer apenas as medidas mínimas. 
Figura 6: Dimensionamento geral dos provadores da loja 2. Fonte: Elaborado pelo autor para a pesquisa (2019).

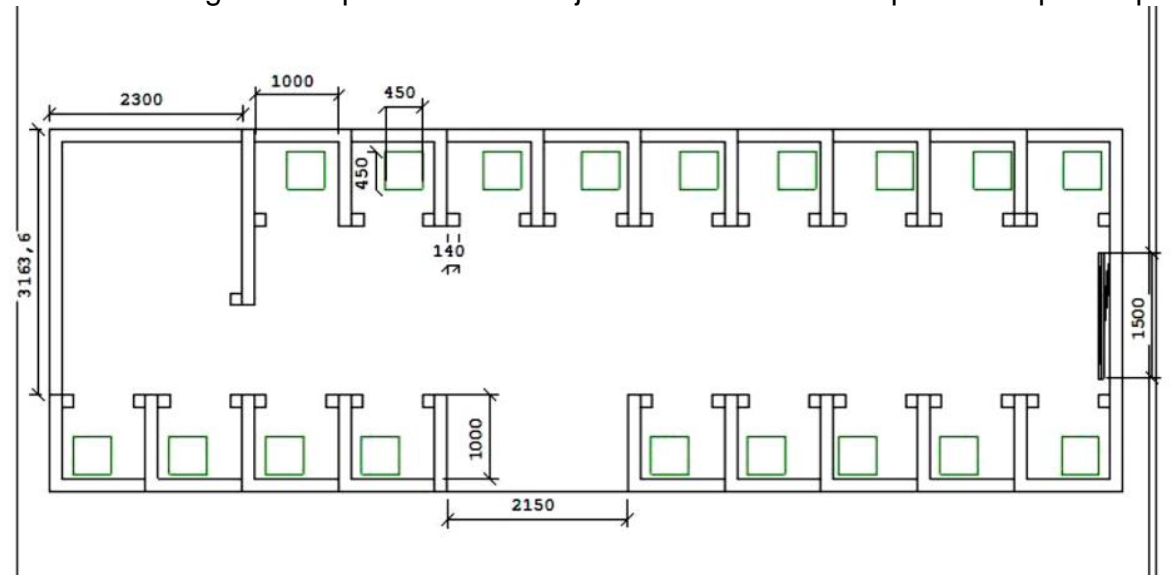

$\mathrm{Na}$ análise de mobiliário, observou-se que o assento oferecido pelo estabelecimento, do tipo pufe, não segue as recomendações sugeridas por Panero e Zelnik (2013). O pufe contém 45cm de largura, o que ultrapassa a média máxima sugerida pelos autores, que é de no máximo de $40,6 \mathrm{~cm}$. No que se refere à altura, o assento mede $45 \mathrm{~cm}$, o que também ultrapassa 0 recomendado de no máximo $40,6 \mathrm{~cm}$. O estudo observou também, os ganchos que suspendem os objetos no interior das cabines. Os atuais suportes estão fixados em uma das paredes, a uma altura de 1,60m, abaixo do valor máximo recomendado pelos autores.

\subsubsection{Provador da loja de departamento 3}

O terceiro provador analisado (figura 7) apresenta $95 \mathrm{~cm}$ de largura, seguido as recomendações de Panero e Zelnik (2013), que sugerem o mínimo de 91,4m de largura para cada cabine, no entanto, o ambiente não oferece as dimensões mínimas em relação a profundidade, que é de apenas $1,15 \mathrm{~m}$, quando o recomendado é de $1,473 \mathrm{~m}$. A área destinada para as portas, que nesta loja são confeccionadas em tecido, mede $95 \mathrm{~cm}$, apresentando-se dentro das recomendações de Panero e Zelnik (2013), os quais sugerem que cada provador tenha no mínimo $61 \mathrm{~cm}$.

Figura 7: Provador da loja de departamento 3. Fonte: Capturado pelo autor para a pesquisa.

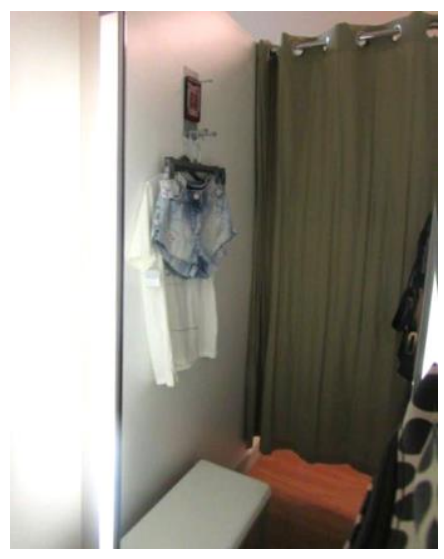

As cabines desse estabelecimento não oferecem molduras laterais no vão da porta, sua 
inexistência pode ocasionar a vulnerabilidade dos usuários nas cabines, podendo gerar desconforto e insegurança. Observou-se ainda que a banqueta oferecida pelo estabelecimento, apresenta 50 centímetros de largura, o que ultrapassa a média máxima sugerida por Panero e Zelnik (2013), que é de no máximo de $40,6 \mathrm{~cm}$. Em relação à altura, o assento mede $42 \mathrm{~cm}, 0$ que também ultrapassa o máximo recomendado de 40,6cm.

Figura 8: Dimensionamento geral do provador da loja 3. Fonte: Elaborado pelo autor para a pesquisa (2019).

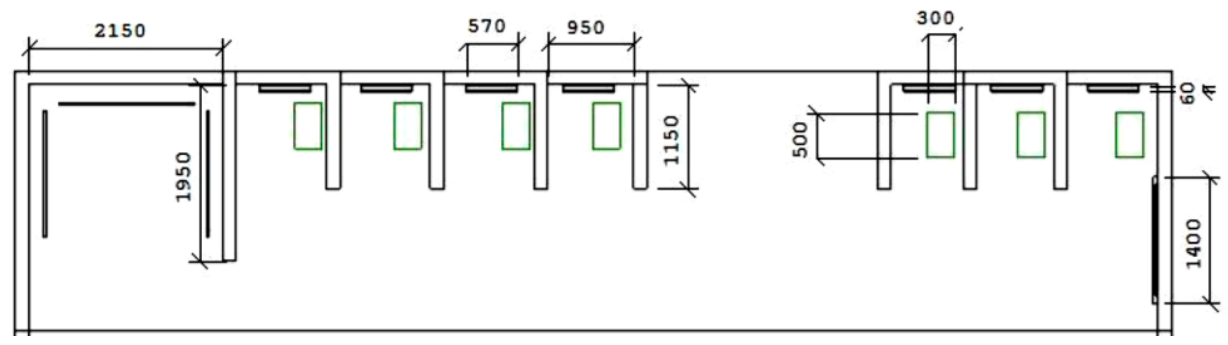

Quanto aos suportes onde estão localizados os ganchos que suspendem os produtos no interior das cabines. Os atuais suportes, estão fixados em duas das paredes do provador, a uma altura de 1,60m, abaixo do valor sugerido por Panero e Zelnik (2013), que é de 1,829m.

\subsubsection{Provador da loja de departamento 4}

O provador analisado (figura 9) apresenta 1,15m de largura, seguindo as recomendações de Panero e Zelnik (2013), que sugerem o mínimo de 91,4cm de largura para cada cabine, porém mesmo adequado, o ambiente não oferece espaço suficiente para seus usuários, pois disponibiliza apenas $1 \mathrm{~m}$ de profundidade, quando o recomendado pelos autores é de 1,473m. Esse tipo de inadequação, além de dificultar as práticas de constantes movimentos na realização da troca de roupa, podem causar lesões ou desconfortos, colocando em risco a integridade física dos consumidores.

Figura 9: Provador da loja de departamento 4: Fonte: Capturado pelo auto para a pesquisa (2019).
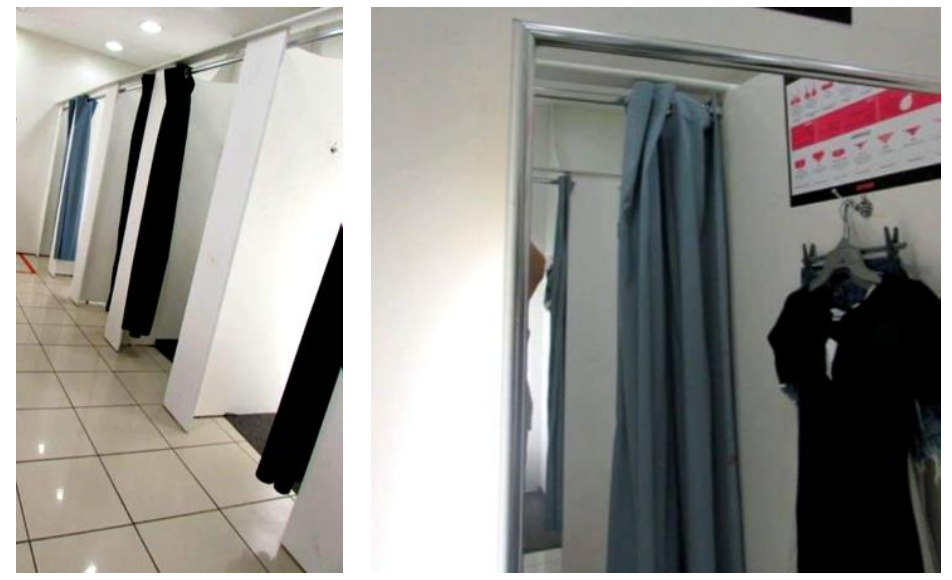

A área que determina os limites das portas mede 1,15m, encaixando-se dentro das recomendações de Panero e Zelnik (2013), que aconselham que, para os provadores serem facilmente acessados, devem medir no mínimo $61 \mathrm{~cm}$, entretanto, nesse caso também, o 
$17^{\circ}$ ERGODESIGN \& USIHC 2019

PUC-Rio, 11 a 13 de dezembro

Rio de Janeiro, RJ, Brasil $17^{\circ}$ Ergodesign - Congresso Internacional de Ergonomia e Usabilidade de Interfaces Humano Tecnológica: Produto, Informações Ambientes Construídos e Transporte

$17^{\circ}$ USIHC - Congresso Internacional de Ergonomia e Usabilidade de Interfaces Humano Computador

estabelecimento oferece duas laterais de segurança, que evitam que as cortinas fiquem entreabertas, medindo $13 \mathrm{~cm}$ cada uma, reduzindo a área total do vão de $1,15 \mathrm{~m}$ para $0,89 \mathrm{~m}$. Explorando essa redução, podemos observar que, mesmo com a perda nas dimensões, a área da porta das cabines ainda atende a recomendação dos autores de $61 \mathrm{~cm}$, mas é importante considerar, o volume extra de produtos que os usuários possuem ao passar por essa área, pode dificultar a entrada no ambiente, se o mesmo não considerar essa possibilidade.

Figura 10: Dimensionamento geral dos provadores da loja 4. Fonte: Elaborado pelo autor para a pesquisa (2019).

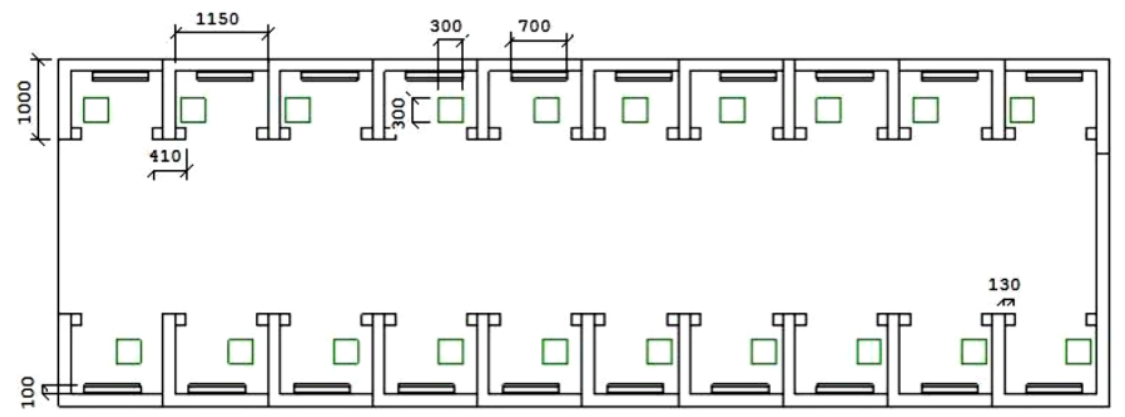

$\mathrm{Na}$ análise do mobiliário de apoio, o assento localizado no interior da cabine apresenta dimensões de $29 \mathrm{~cm}$ de largura, abaixo da média sugerida por Panero e Zelnik (2013), que definem a medida mínima de $30,5 \mathrm{~cm}$, podendo chegar ao máximo de $40,6 \mathrm{~cm}$. Em relação à altura, o banco mede $40 \mathrm{~cm}$, o que corresponde ao recomendado pelos autores, que é de no máximo 40,6cm. Como podemos analisar, a banqueta oferecida pela loja possui dimensões de largura inferiores ao recomendado, o que pode dificultar a utilização do mobiliário por pessoas com determinados biótipos, como indivíduos endomorfos por exemplo.

O estudo analisou também a altura dos suportes que contém os ganchos que apoiam os objetos no interior das cabines. Os suportes estão fixados em duas das paredes, a uma altura de 1,60m, abaixo da média máxima sugerida por Panero e Zelnik (2013), que é de 1,829m.

\subsection{Análise da usabilidade dos elementos físicos}

Para melhor compreensão, bem como síntese dos resultados analíticos, os elementos identificados nesta etapa da pesquisa serão apresentados em um quadro, o qual apresenta os pontos físicos de inadequação identificados sob o ponto de vista da abordagem dos três usuários referência no estudo: estatura elevada, sobrepeso e estatura baixa. 


\section{$17^{\circ}$ ERGODESIGN \& USIHC 2019}

PUC-Rio, 11 a 13 de dezembro

Rio de Janeiro, RJ, Brasil $17^{\circ}$ Ergodesign - Congresso Internacional de Ergonomia e Usabilidade de Interfaces Humano Tecnológica: Produto, Informações Ambientes Construídos e Transporte

$17^{\circ}$ USIHC - Congresso Internacional de Ergonomia e Usabilidade de Interfaces Humano Computador

Quadro 1: Síntese das inadequações na usabilidade dos elementos físicos. Fonte: Capturado e elaborado pelo autor para a pesquisa (2019).

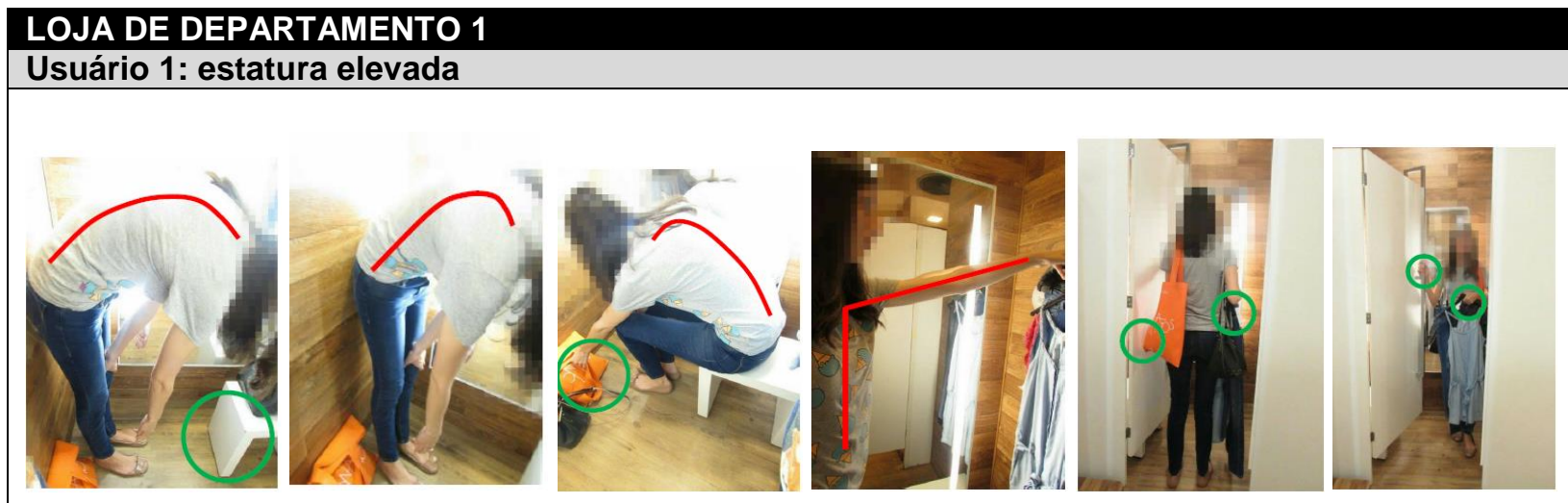

\section{Usuário 2: sobrepeso}
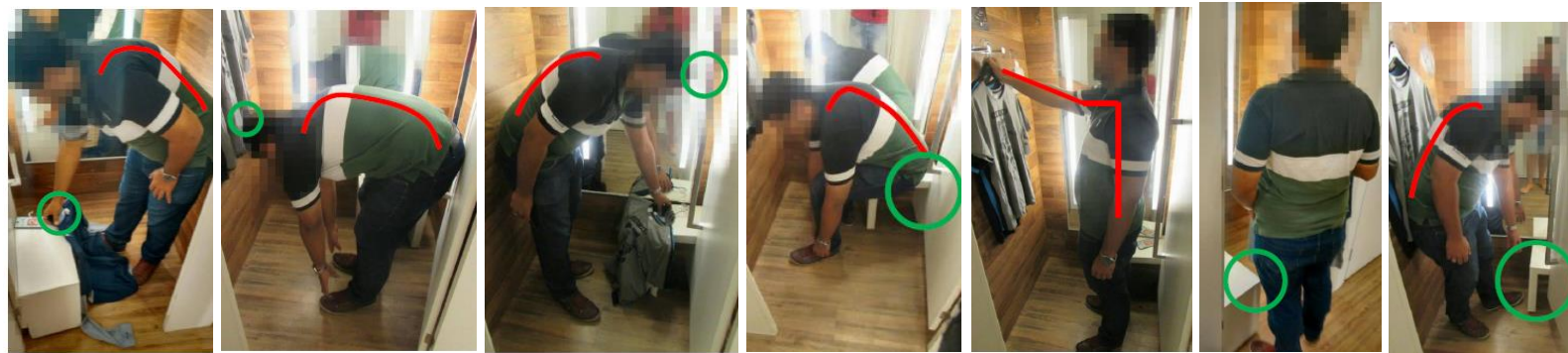

\section{Usuário 3: baixa estatura}
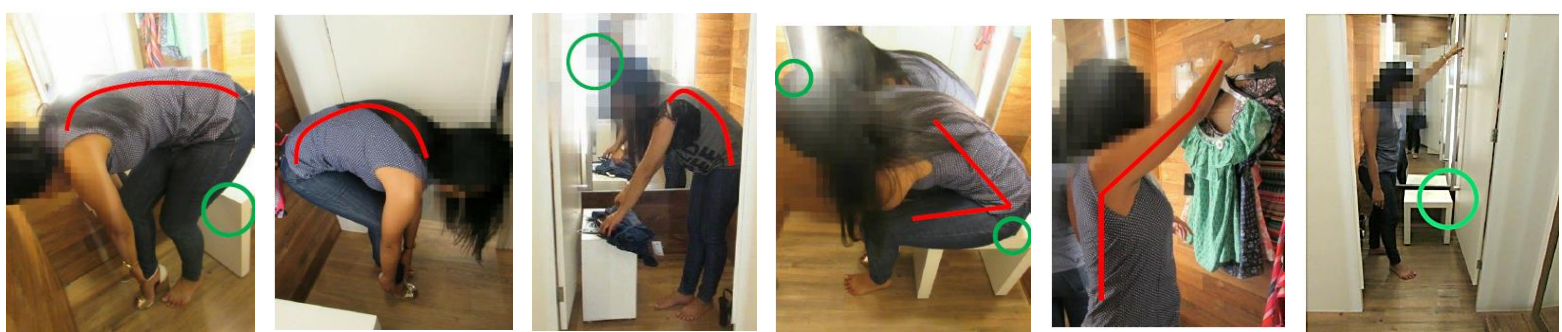

Dificuldades encontradas:

- A banqueta dificulta atividades que envolvam flexão do tronco por ocupar espaço interno;

- Pouco espaço para flexão acentuada do tronco com o indivíduo de pé;

- Pouco espaço para flexão acentuada do tronco com o indivíduo sentado na banqueta;

- Elevação de membro superior para alcançar as peças de vestuário no gancho;

- Vão de porta estreito quando se faz necessário entrar transportando bolsas e artigos;

- Circulação comprometida no interior da cabine devido à abertura interna da porta. 


\section{$17^{\circ}$ ERGODESIGN \& USIHC 2019}

PUC-Rio, 11 a 13 de dezembro

Rio de Janeiro, RJ, Brasil $17^{\circ}$ Ergodesign - Congresso Internacional de Ergonomia e Usabilidade de Interfaces Humano Tecnológica: Produto, Informações Ambientes Construídos e Transporte

$17^{\circ}$ USIHC - Congresso Internacional de Ergonomia e Usabilidade de Interfaces Humano Computador

\section{LOJA DE DEPARTAMENTO 2 \\ Usuário 1: estatura elevada

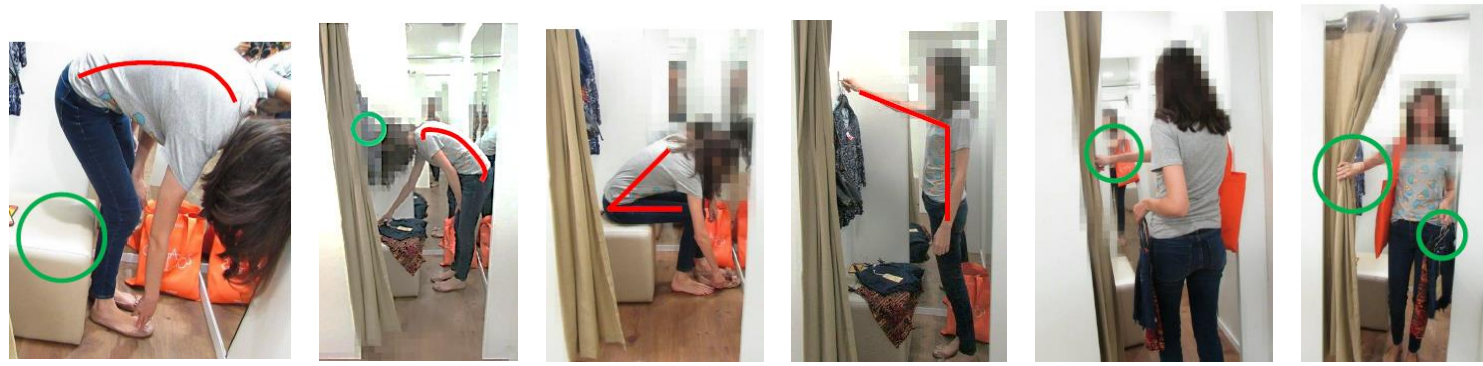

\section{Usuário 2: sobrepeso}
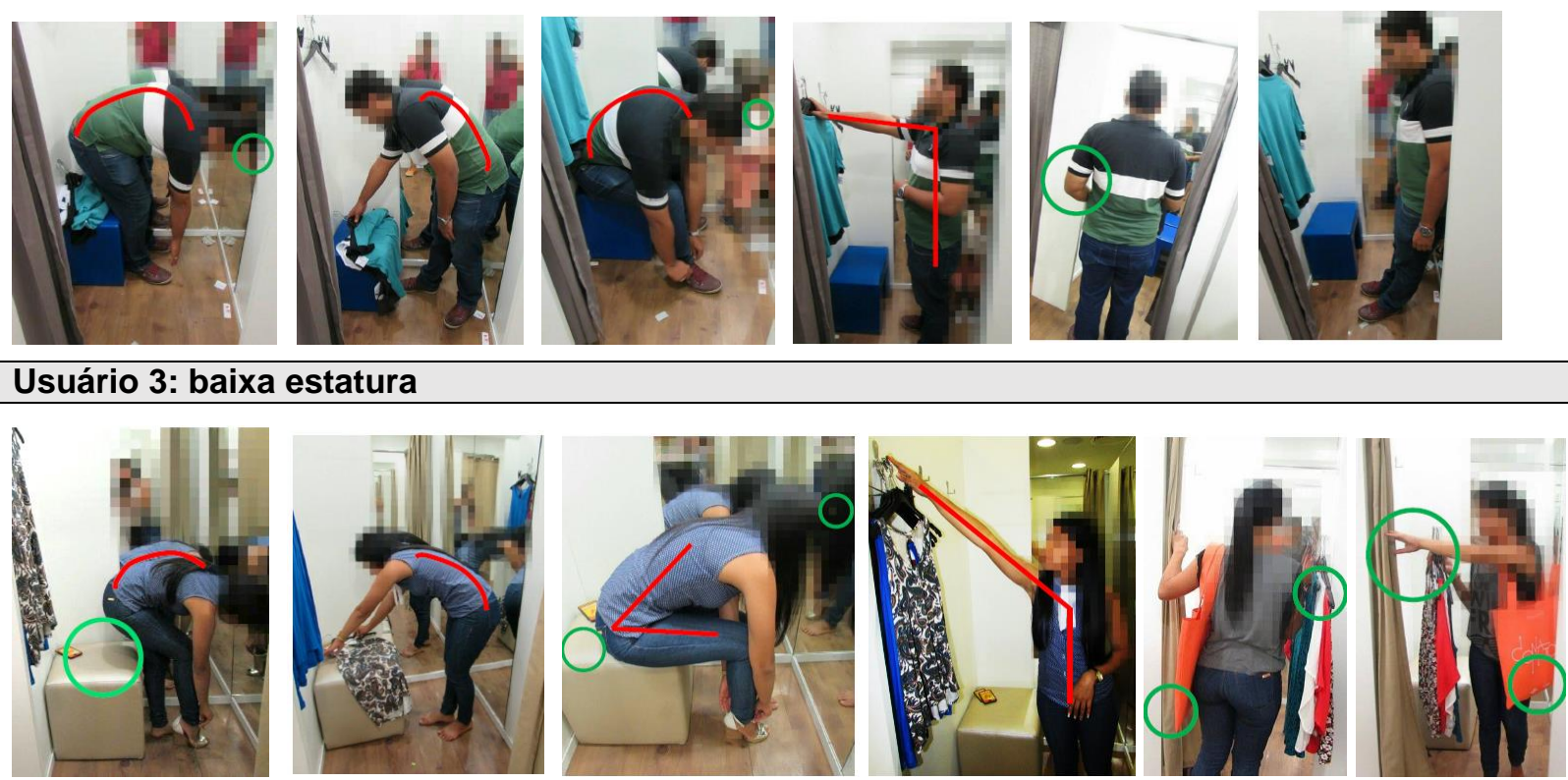

Dificuldades encontradas:

- A dimensão do pufe dificulta atividades que envolvam flexão do tronco por ocupar espaço interno;

- Pouco espaço para flexão acentuada do tronco com o indivíduo de pé (estatura elevada e sobrepeso);

- Pouco espaço para flexão acentuada do tronco com o indivíduo sentado no pufe;

- Elevação de membro superior para alcançar as peças de vestuário no gancho;

- Vão de entrada estreito quando se faz necessário entrar transportando bolsas e artigos;

- Amplitude de movimentos comprometida no interior da cabine devido à reduzida dimensão do espaço.

LOJA DE DEPARTAMENTO 3

Usuário 1: estatura elevada
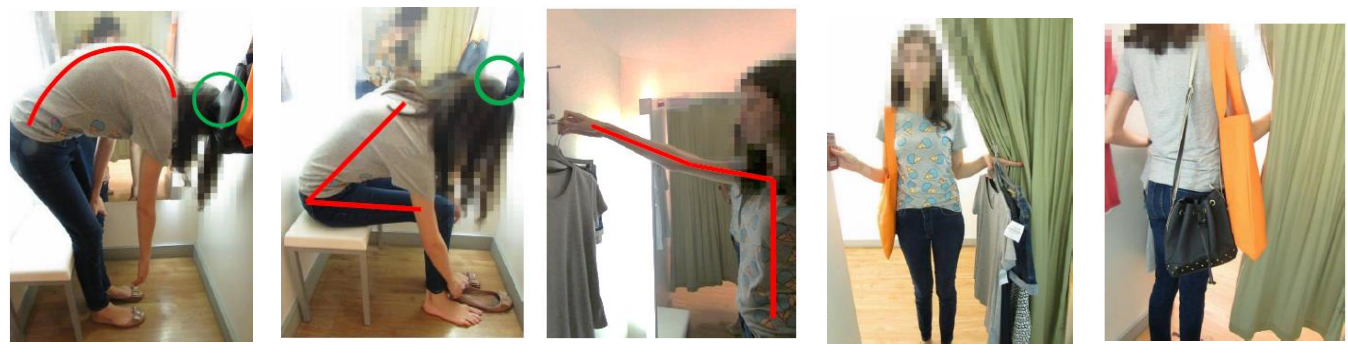


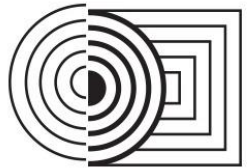

\section{$17^{\circ}$ ERGODESIGN \& USIHC 2019}

PUC-Rio, 11 a 13 de dezembro

Rio de Janeiro, RJ, Brasil $17^{\circ}$ Ergodesign - Congresso Internacional de Ergonomia e Usabilidade de Interfaces Humano Tecnológica: Produto, Informações Ambientes Construídos e Transporte

$17^{\circ}$ USIHC - Congresso Internacional de Ergonomia e Usabilidade de Interfaces Humano Computador
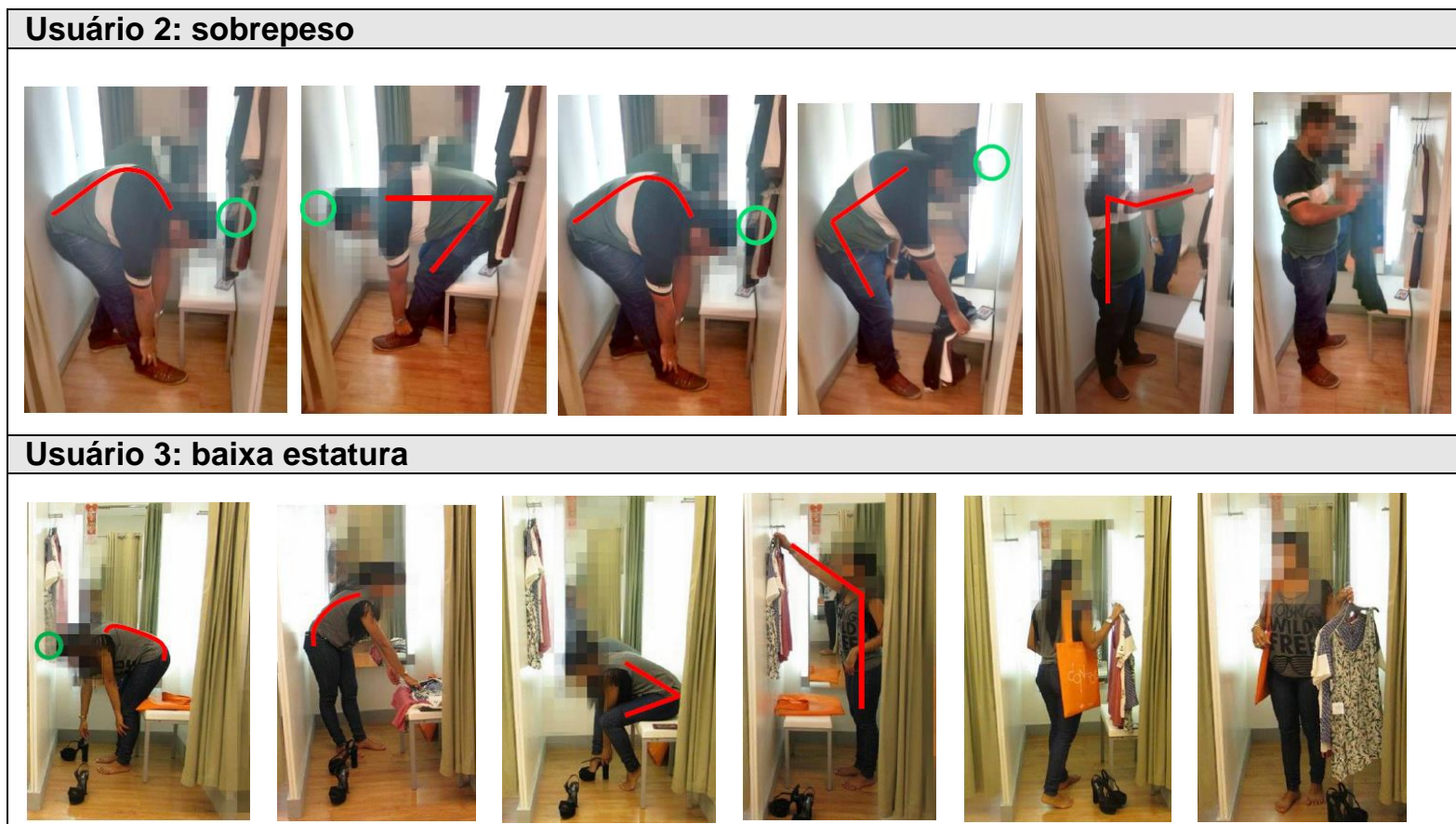

Dificuldades encontradas:

- A dimensão da banqueta dificulta atividades que envolvam flexão do tronco por ocupar espaço interno;

- Pouco espaço para flexão acentuada do tronco com o indivíduo de pé (estatura elevada e sobrepeso);

- Pouco espaço para flexão do tronco e indivíduo sentado na banqueta (estatura elevada e sobrepeso);

- Elevação de membro superior para alcançar as peças de vestuário no gancho;

- Vão de entrada estreito quando se faz necessário entrar transportando bolsas e artigos (sobrepeso); - Amplitude de movimentos comprometida no interior da cabine devido à reduzida dimensão do espaço (estatura elevada e sobrepeso).

\section{LOJA DE DEPARTAMENTO 4}

\section{Usuário 1: estatura elevada}
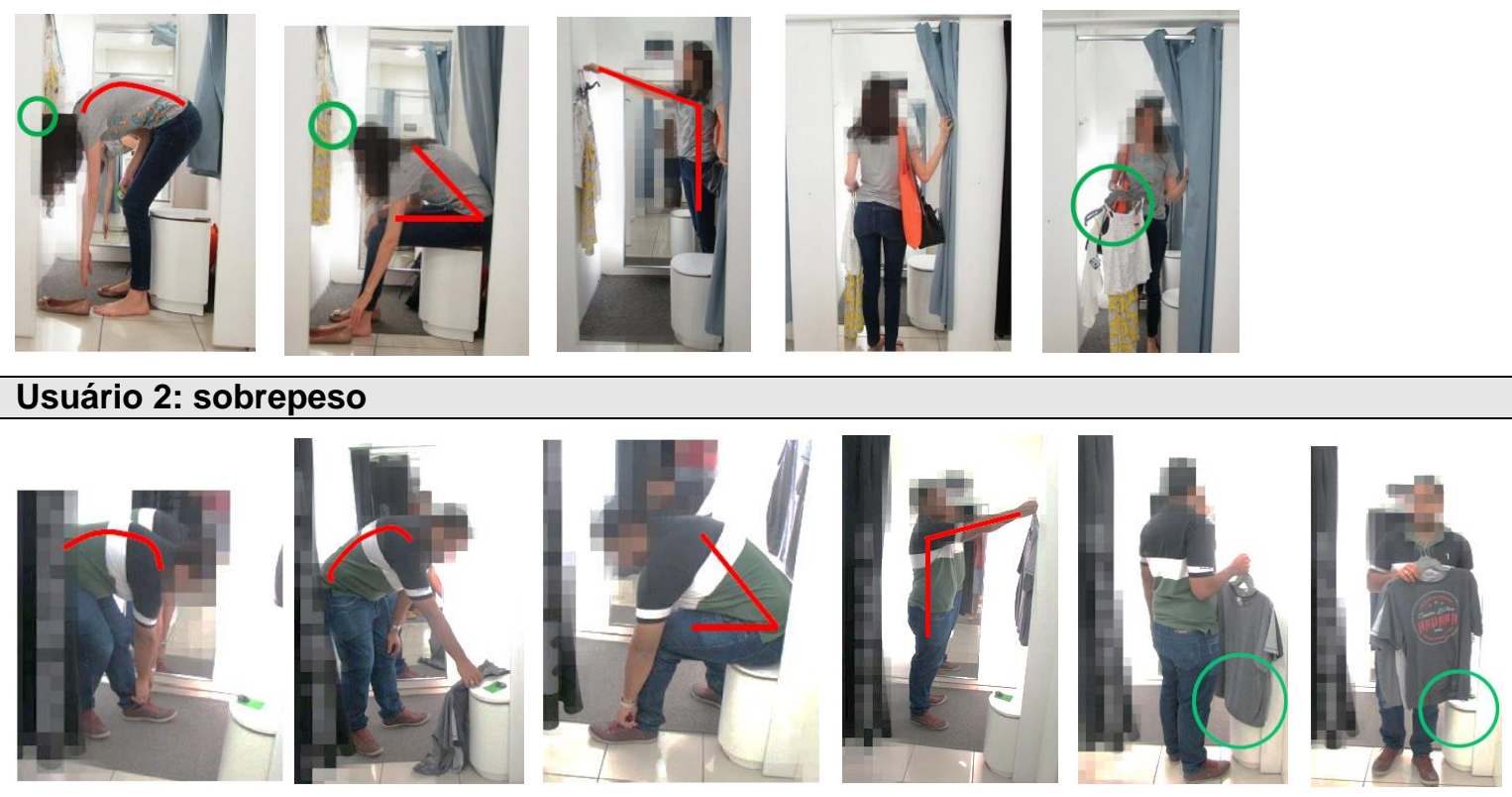


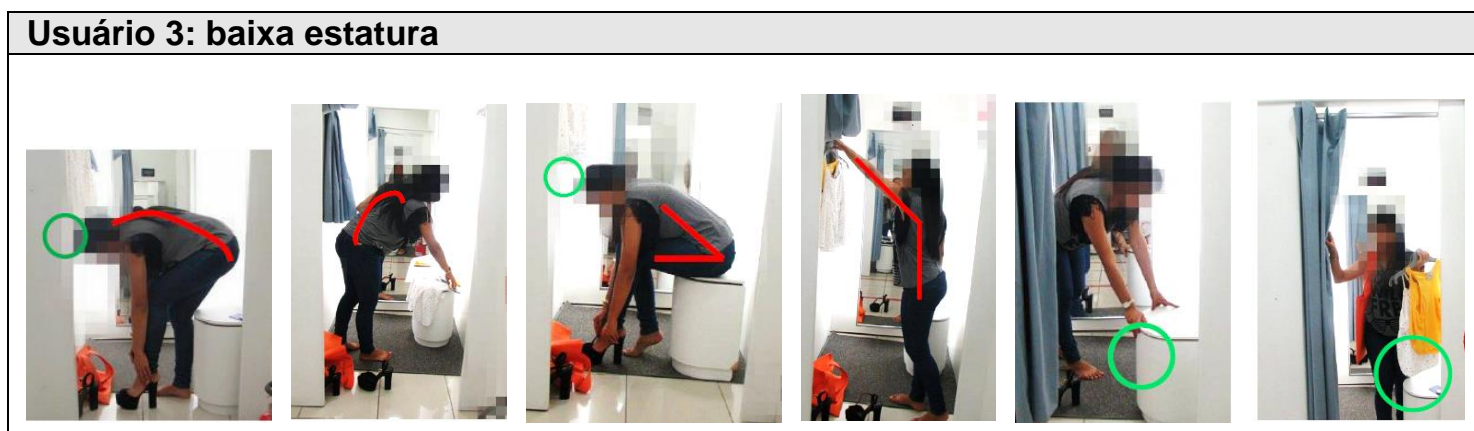

Dificuldades encontradas:

- A dimensão do pufe dificulta atividades que envolvam flexão do tronco, por ocupar espaço interno;

- Pouco espaço para flexão acentuada do tronco com o indivíduo de pé (estatura elevada);

- Elevação de membro superior para alcançar as peças de vestuário no gancho;

- Vão de entrada estreito quando se faz necessário entrar transportando bolsas e artigos (sobrepeso);

- Amplitude de movimentos comprometida no interior da cabine devido à reduzida dimensão do espaço (estatura elevada e sobrepeso).

A análise expôs diversos pontos que evidenciam a dificuldade na usabilidade dos elementos físicos das cabines, bem como assunções posturais que se distanciam de angulações neutras das articulações e coluna vertebral. Diversas inadequações se repetem em todas as cabines investigadas e, dependendo da atividade, com maior intensidade para alguns dos usuários analisados (quadro 2).

Quadro 2: Análise comparativa das inadequações encontradas.

\begin{tabular}{|c|c|c|c|c|c|c|c|c|c|c|c|c|}
\hline & \multicolumn{3}{|c|}{ Loja 1} & \multicolumn{3}{|c|}{ Loja 2} & \multicolumn{3}{|c|}{ Loja 3} & \multicolumn{3}{|c|}{ Loja 4} \\
\hline INADEQUAÇÕES & U1 & U2 & U3 & U1 & U2 & U3 & U1 & U2 & U3 & U1 & U2 & U3 \\
\hline $\begin{array}{l}\text { DIFICULDADE PARA } \\
\text { FLEXIONAR O TRONCO A } 90^{\circ} \mathrm{C} / \text { BANCO }\end{array}$ & $\mathbf{x}$ & $\mathbf{x}$ & $\mathbf{x}$ & $\mathbf{x}$ & $\mathbf{x}$ & $\mathbf{x}$ & $\mathbf{x}$ & $\mathbf{X}$ & $\mathbf{X}$ & $\mathbf{x}$ & $\mathbf{X}$ & $\mathbf{x}$ \\
\hline $\begin{array}{l}\text { DIFICULDADE PARA } \\
\text { FLEXIONAR O TRONCO A } 90^{\circ} \mathrm{S} / \text { BANCO }\end{array}$ & $\mathbf{x}$ & $\mathbf{x}$ & $\mathbf{x}$ & $\mathbf{x}$ & $\mathbf{X}$ & $\mathbf{x}$ & $\mathbf{x}$ & $\mathbf{X}$ & $\mathbf{x}$ & $\mathbf{x}$ & $\mathbf{x}$ & $\mathbf{x}$ \\
\hline $\begin{array}{l}\text { DIFICULDADE PARA } \\
\text { FLEXIONAR O TRONCO A } 70^{\circ}\end{array}$ & & $\mathbf{x}$ & $\mathbf{x}$ & $\mathbf{x}$ & $\mathbf{X}$ & $\mathbf{x}$ & & $\mathbf{X}$ & $\mathbf{x}$ & & $\mathbf{x}$ & $\mathbf{x}$ \\
\hline $\begin{array}{l}\text { DIFICULDADE PARA } \\
\text { FLEXIONAR E SENTAR COM O TRONCO A } 135^{\circ}\end{array}$ & $\mathbf{x}$ & $\mathbf{x}$ & $\mathbf{x}$ & $\mathbf{x}$ & $\mathbf{X}$ & $\mathbf{x}$ & $\mathbf{x}$ & $\mathbf{X}$ & $\mathbf{x}$ & $\mathbf{x}$ & $\mathbf{x}$ & $\mathbf{x}$ \\
\hline $\begin{array}{l}\text { DIFICULDADE EM } \\
\text { APOIAR ROUPAS NOS GANCHOS }\end{array}$ & $\mathbf{x}$ & $\mathbf{x}$ & $\mathbf{x}$ & $\mathbf{x}$ & $\mathbf{x}$ & $\mathbf{x}$ & $\mathbf{x}$ & $\mathbf{x}$ & $\mathbf{x}$ & $\mathbf{x}$ & $\mathbf{x}$ & $\mathbf{x}$ \\
\hline $\begin{array}{l}\text { DIFICULDADE EM } \\
\text { PASSAR PELO VÃO DA PORTA }\end{array}$ & $\mathbf{x}$ & $\mathbf{x}$ & $\mathbf{x}$ & & $\mathbf{x}$ & $\mathbf{x}$ & & & & $\mathbf{X}$ & $\mathbf{x}$ & $\mathbf{x}$ \\
\hline $\begin{array}{l}\text { DIFICULDADE EM } \\
\text { LOCOMOÇÃO }\end{array}$ & $\mathbf{x}$ & $\mathbf{x}$ & $\mathbf{x}$ & & $\mathbf{x}$ & $\mathbf{x}$ & $\mathbf{x}$ & & & $\mathbf{x}$ & & $\mathbf{x}$ \\
\hline
\end{tabular}

Diversas foram as inadequações encontradas, mas algumas delas se apresentaram de forma mais intensa e evidente. A estatura elevada revelou comprometimentos mais severos nas flexões do tronco e abdução de membros superiores dentro do espaço, o sobrepeso dificultou a entrada na cabine e a circulação interna, a baixa estatura encontra dificuldades intensas no alcance superior para aquisição das roupas nos ganchos. 
$17^{\circ}$ ERGODESIGN \& USIHC 2019

PUC-Rio, 11 a 13 de dezembro

Rio de Janeiro, RJ, Brasil $17^{\circ}$ Ergodesign - Congresso Internacional de Ergonomia e Usabilidade de Interfaces Humano Tecnológica: Produto, Informações Ambientes Construídos e Transporte

$17^{\circ}$ USIHC - Congresso Internacional de Ergonomia e Usabilidade de Interfaces Humano Computador

Sugestões de melhoria para a cabine da loja de departamento 1:

- Propor a fixação de 2 suportes por cabine contendo cada um dos suportes 3 ganchos, totalizando o número de 6 ganchos por cabine. Acrescentando ainda a fixação de 1 gancho separado em cada lado da cabine para a plaqueta de quantitativo de peças e para uma bolsa grande. Esse número de ganchos é visto como suficiente para atender a demanda sem comprometer o espaço físico e organizacional do ambiente;

- A fixação dos suportes deve ser realizada em alturas alternadas, considerando sempre a altura máxima de $1,82 \mathrm{~cm}$. Essa recomendação contribui para que as pessoas com menores estaturas possam utilizar os ganchos com qualidade e menores esforços;

- Especificar um assento que tenha o mínimo de $30,5 \mathrm{~cm}$ à 40,6cm de largura por 40,6cm de altura. Essas medidas são suficientes para atender do maior ao menor indivíduo com conforto e segurança;

- Posicionar a banqueta do lado contrário a porta, evitando o atrito de ambos;

- Especificar portas de articulação retrátil (sanfonada), que facilite circulação e assegure a privacidade dos usuários;

- Eliminar a dimensão sacada do espelho (que é de $15 \mathrm{~cm}$ ), ampliando o espaço interno da cabine;

- Eliminar uma das cabines da loja e redistribuir seu espaço entre as cabines restantes, ampliando o espaço interno destas, oferecendo-se o mínimo de 91,4cm de largura, por $147,3 \mathrm{~cm}$ de profundidade.

Sugestões de melhoria para a cabine da loja de departamento 2:

- Fixar 2 ganchos suportes por cabine, contendo cada um dos suportes 3 ganchos, totalizando o número de 6 ganchos por cabine. Acrescentando ainda a fixação de 1 gancho separado em cada lado da cabine para a plaqueta de quantitativo de peças e para uma bolsa grande. Esse número de ganchos é visto como suficiente para atender as demandas sem comprometer o espaço físico e organizacional do ambiente;

- A fixação dos suportes deve ser realizada em alturas alternadas, considerando sempre a altura máxima de $1,82 \mathrm{~cm}$. Essa recomendação contribui para que as pessoas com menores estaturas possam utilizar os ganchos com qualidade e menor esforço;

- Oferecer um assento que apresente o mínimo de $30,5 \mathrm{~cm}$ à 40,6 cm de largura por, no máximo, 40,6cm de altura. Essas medidas são suficientes para atender do maior ao menor indivíduo com conforto, segurança e bem-estar;

- Reduzir a largura das abas laterais do vão da porta de $14 \mathrm{~cm}$ para $10 \mathrm{~cm}$, oferecendo mais espaço para entrada na cabine; 
$17^{\circ}$ ERGODESIGN \& USIHC 2019

PUC-Rio, 11 a 13 de dezembro

Rio de Janeiro, RJ, Brasil $17^{\circ}$ Ergodesign - Congresso Internacional de Ergonomia e Usabilidade de Interfaces Humano Tecnológica: Produto, Informações Ambientes Construídos e Transporte

$17^{\circ}$ USIHC - Congresso Internacional de Ergonomia e Usabilidade de Interfaces Humano Computador

- Eliminar uma das cabines da loja e redistribuir seu espaço entre as cabines restantes, ampliando o espaço interno destas, oferecendo-se o mínimo de 91,4cm de largura, por $147,3 \mathrm{~cm}$ de profundidade.

Sugestões de melhoria para a cabine da loja de departamento 3:

- Inserção de abas laterais de $10 \mathrm{~cm}$ na moldura do vão da porta, oferecendo maior privacidade ao proteger as laterais da cortina;

- Oferecer um assento que apresente o mínimo de $30,5 \mathrm{~cm}$ à 40,6cm de largura por, no máximo, 40,6cm de altura. Essas medidas são suficientes para atender do maior ao menor indivíduo com conforto, segurança e bem-estar;

- Propor fixação dos suportes em alturas alternadas, considerando sempre a altura de $1,82 \mathrm{~cm}$ máx. Essa recomendação contribui para que as pessoas com menores estaturas possam utilizar os ganchos com qualidade e menor esforço;

- Eliminar a dimensão sacada do espelho, ampliando o espaço interno da cabine;

- Eliminar uma das cabines da loja e redistribuir seu espaço entre as cabines restantes, ampliando o espaço interno destas, oferecendo-se o mínimo de 91,4cm de largura, por $147,3 \mathrm{~cm}$ de profundidade.

Sugestões de melhoria para a cabine da loja de departamento 4:

- Instalar 2 ganchos suporte por cabine, contendo cada um dos suportes 3 ganchos, totalizando o número de 6 ganchos por cabine. Evitando que o usuário utilize outros meios para suspender seus objetos;

- Propor fixação dos suportes em alturas alternadas, considerando sempre a altura de $1,82 \mathrm{~cm}$ máx. Essa recomendação contribui para que as pessoas com menores estaturas possam utilizar os ganchos com qualidade e menor esforço;

- Oferecer um assento que apresente o mínimo de 30,5cm à 40,6cm de largura por, no máximo, 40,6cm de altura. Essas medidas são suficientes para atender do maior ao menor indivíduo com conforto, segurança e bem-estar;

- Reduzir a largura das abas laterais do vão da porta de $13 \mathrm{~cm}$ para $10 \mathrm{~cm}$, oferecendo mais espaço para entrada na cabine;

- Eliminar uma das cabines da loja e redistribuir seu espaço entre as cabines restantes, ampliando o espaço interno destas, oferecendo-se o mínimo de 91,4cm de largura, por $147,3 \mathrm{~cm}$ de profundidade. 


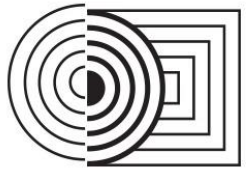

$17^{\circ}$ ERGODESIGN \& USIHC 2019

PUC-Rio, 11 a 13 de dezembro

Rio de Janeiro, RJ, Brasil $17^{\circ}$ Ergodesign - Congresso Internacional de Ergonomia e Usabilidade de Interfaces Humano Tecnológica: Produto, Informações Ambientes Construídos e Transporte

$17^{\circ}$ USIHC - Congresso Internacional de Ergonomia e Usabilidade de Interfaces Humano Computador

\section{CONCLUSÃO}

Este estudo sugere que o projeto de espaços com dimensões reduzidas necessita adequar-se às necessidades de quem faz uso do ambiente, principalmente se esse ambiente for um estabelecimento comercial onde atende uma grande variação dimensional de usuários. A inadequada configuração do ambiente pode acarretar prejuízos à saúde dos usuários, pondo-o em risco de lesões temporárias a permanentes devido à falta de foco na concepção de um projeto relacionando às dimensões do ambiente e do usuário.

Mediante as ferramentas de Antropometria aplicadas nesse estudo, verificou-se que o espaço oferecido pelos provadores apresenta condições pouco adequadas para atender, de maneira satisfatória e segura, os biotipos dos voluntários da pesquisa. Observou-se também que a organização dos equipamentos e mobiliário de apoio costuma interferir no espaço livre das cabines comprometendo o desempenho de suas atividades.

Deste modo, faz necessário repousar o olhar ergonômico para projetos de espaços e artefatos direcionados a características distintas de usuários. Indivíduos de estatura elevada, baixa estatura e com sobrepeso interagem cotidianamente com os mesmos espaços e artefatos que os demais indivíduos da sociedade, sendo assim, faz-se necessário uma igual atenção projetual. É possível atender a todos os usuários com projetos únicos e, para tanto, deve-se estimular a captação de informações projetuais acerca dos diferentes biotipos que compõem uma população.

\section{REFERÊNCIAS BIBLIOGRÁFICAS}

BINS ELY, Vera Helena Moro. Acessibilidade Espacial-condição necessária para o projeto de ambientes inclusivos. In: Ergodesign do Ambiente Construído e Habitado: Ambiente Urbano, Ambiente Público, Ambiente Laboral. Rio de Janeiro: IUsEr, 2004.

FERRAZ De Lima, Carlos Roberto; GORGATTI, Márcia Greguol; DUTRA, Milena CARRIJO. A influência do esporte na qualidade de vida das pessoas com deficiência visual the influence of sports on quality of life of people with visual disabilities. Revista de atenção à saúde (antiga rev. Bras. Ciên. Saúde), v. 8, n. 23, 2010.

IIDA, Itiro. Ergonomia: projeto e produção. 3 ed. revisada e ampliada. São Paulo: Edgard Blucher, 2005.

PANERO, Julius; ZELNIK, Martins. Dimensionamento humano para espaços interiores, Editor Gustavo Gili, SL, Barcelona, 2013.

SANTOS, R; FUJÃO, C. Antropometria. Évora, Espirito Santo, 2003. Disponível em: <http://www.histeo.dec.ufms.br/materiais/projetodeinteriores/04\%20-\%20Antropometria\%20\%20Raquel\%20Santos\%20e\%20Carlos\%20Fujao.pdf>. Acesso em: 1 junho 2019.

TRAMONTIN, Ana Cristina. Identificação dos itens de demanda ergonômica em lojas de cosméticos e perfumes. Dissertação de mestrado. Programa de Pós-Graduação em Engenharia de Produção. Universidade Federal do Rio Grande do Sul. Porto Alegre, 2000. 


\section{$17^{\circ}$ ERGODESIGN} \& USIHC 2019

PUC-Rio, 11 a 13 de dezembro

Rio de Janeiro, RJ, Brasil $17^{\circ}$ Ergodesign - Congresso Internacional de Ergonomia e Usabilidade de Interfaces Humano Tecnológica: Produto, Informações Ambientes Construídos e Transporte

$17^{\circ}$ USIHC - Congresso Internacional de Ergonomia e Usabilidade

de Interfaces Humano Computador

\section{AGRADECIMENTOS}

Agradecemos às lojas de departamento, as quais permitiram nossa entrada e desenvolvimento da pesquisa em suas instalações. Também somos imensamente gratos aos voluntários da pesquisa, pois pacientemente realizaram a troca das peças de roupa e autorizaram 0 acompanhamento da tarefa no interior das cabines. 